\title{
A TEORIA DOS PRINCÍPIOS NA TEORIA JURÍDICA BRASILEIRA: AS CONTRIBUIÇÕES DE THOMAS BUSTAMANTE PARA O DEBATE
}

\section{Jamir Calili Ribeiro ${ }^{1}$}

Resumo: O tema do artigo são as contribuições teóricas desenvolvidas pelo pensador mineiro Thomas Bustamante, que influenciado pela Teoria dos Princípios de Robert Alexy, apresenta uma teoria própria acerca da diferenciação entre princípios e regras e desenvolve a sua utilidade na argumentação jurídica. A grande contribuição do autor para a teoria do direito é o aperfeiçoamento da ideia de superabilidade das normas jurídicas. $\mathrm{O}$ artigo, por meio de uma revisão bibliográfica, revisita crítica e reflexivamente os argumentos do autor, analisando-os e apontando seus pontos fracos e fortes.

Palavras-chave: teoria dos princípios; teoria do direito; argumentação jurídica; teoria da norma; princípios e regras

\section{PRINCIPLES THEORY IN BRAZILIAN LEGAL THEORY: THOMAS BUSTAMANTE'S CONTRIBUTIONS TO THE DEBATE}

Abstract: The subject of the article is the theoretical contributions developed by the Minas Gerais thinker Thomas Bustamante, who, influenced by Robert Alexy's Theory of Principles, presents his own theory about the differentiation between principles and rules and develops its usefulness in legal argumentation. The great contribution of the author to the theory of law is the improvement of the idea of overcoming legal norms. The article, through a bibliographic review, critically and reflexively revisits the author's arguments, analyzing them and pointing out their weaknesses and strengths.

Keywords: principle theory; law theory; legal argumentation; norm theory; principles and rules

\section{1 - INTRODUÇÃO}

É comum a doutrina, em todos os setores da investigação do direito, asseverar a existência de "princípios jurídicos", especialmente em contraponto às chamadas regras jurídicas. Embora haja uma repercussão significativa, através da publicação de diversos artigos, sobre os princípios jurídicos, a distinção entre espécies normativas, princípios e

\footnotetext{
${ }^{1}$ Doutor em Direito pela PUC - Minas. Mestre em Administração Pública pela FJP. Bacharel em Direito pela PUC -Minas. Bacharel em Ciências Sociais pela UFMG. Professor Adjunto III da UFJF-GV. E-mail: jamir.calili@ufjf.edu.br
} 
regras, não é pacífica nos debates doutrinários e jurisprudenciais, gerando vasta literatura - o que, a princípio, não é um problema, uma vez que é natural conceitos serem tratados, pragmaticamente, com sentidos diversos.

Para Álvaro Ricardo de Souza Cruz, “o debate atual sobre a 'teoria dos princípios' e a distinção das espécies normativas (...) devem ser atribuídos a Ronald Dworkin” (2007, p. 37). Segundo ele, desde a edição do texto "O modelo de regras I" houve verdadeira ruptura do arcabouço jurídico positivista, descortinando uma perspectiva de uma hermenêutica crítica e pós-positivista.

Humberto Ávila ressalta que os estudos de direito público lograram significativos avanços em relação à interpretação e aplicação das normas jurídicas. Desse modo, havendo uma preponderância e euforia acerca dos princípios jurídicos como normas a serem interpretadas e aplicadas, o autor sugere a necessidade de compreender o que são afinal essas entidades normativas. Destaca ainda o autor que a doutrina constitucional tem se referido ao Estado Constitucional contemporâneo como Estado Principiológico (ÁVILA, 2012, p. 27).

Como se pode notar, ambos os autores relevam que a teoria dos princípios parece ser um avanço no modelo hermenêutico, superando uma visão menos estreita do que seria a aplicação do direito, própria do positivismo jurídico.

Ocorre que, ao mesmo tempo em que se tem um amplo debate sobre a existência de diferentes espécies normativas e suas principais distinções, parece, em uma primeira constatação, que há, na doutrina, uma profusão de conceitos e classificações sobre regras e princípios, que os emprega de forma assistemática e não científica. E aqui que mora o problema: a atribuição de sentidos não apropriados que revelam fragilidade sistémica para a decisão.

Diversos autores (por ex. GALUPPO, 2002; BUSTAMANTE, 2006; CRUZ, 2007; ÁVILA, 2012) percebem que a distinção adotada entre princípios e regras não é clara dentro dos debates estabelecidos na doutrina e, muitas vezes, há o uso impróprio das distinções teóricas já elaboradas, em um sincretismo perigoso e não sistematizado de forma adequada. Isso leva a alguns equívocos, tais como a exaltação exagerada da importância dos princípios apequenando as funções das regras. Além disso, a correlação feita entre princípios e valores leva à ideia de que o aplicador das normas poderá utilizar-se de apreciações subjetivas, o que tornaria a investigação judicial incontrolável (ÁVILA, 2012, p.27-28). 
Como se vê, trata-se de uma hipótese sobre o comportamento da doutrina jurídica nacional, sendo necessária uma investigação mais apurada sobre esse comportamento, o que não será o objeto deste artigo.

Humberto Ávila (2012, p. 28), ao introduzir o seu livro Teoria dos Princípios, defende que é necessário compreender a distinção entre princípios e regras especialmente pelo relevo que vem ganhando nos debates doutrinários e jurisprudenciais (ÁVILA, 2012, p. 28).

Por fim, destaca-se Bustamante, reconhecendo, também, a importância desse tipo de estudo, ressaltando o sucesso da teoria alexyana em solo nacional e como a ideia de que normas constitucionais podem ser classificadas como princípios ou regras ganhou força desde as Universidades ao Supremo Tribunal Federal, força essa poucas vezes vivenciada por qualquer concepção jurídico-normativa (BUSTAMANTE, 2008, p. 77).

Como se pode ver pelos exemplos citados, é reconhecida a importância da distinção entre regras e princípios da construção doutrinária e jurisprudencial.

O que se pretende fazer neste artigo, portanto, é um estudo sistematizado específico do pensamento de um pesquisador brasileiro, Thomas de Rosa Bustamante (2002; 2005; 2006; 2010a; 2010b; 2012), professor da Universidade Federal de Minas Gerais, e que é referência nacional na teoria de Robert Alexy, mas que não encampou acriticamente a teoria. O pesquisador mineiro traz importantes contribuições ao debate teórico e prático que instiga uma revisão e análise. É o que se pretende fazer aqui neste artigo, por meio de uma revisão bibliográfica: Como a teoria jurídica brasileira incorporou a teoria dos princípios? Para responder essa pergunta, tomamos como base o teórico mineiro, delimitando-se assim esse trabalho ao estudo da Teoria dos Princípios sob a ótica de Thomas Bustamante, fazendo-se um estudo da forma como a teoria jurídica nacional recebeu a teoria a partir das contribuições deste pesquisador.

\section{2 - A INFLUÊNCIA DE ROBERT ALEXY}

A teoria de Alexy (2005; 2007; 2014a; 2014b; 2012) encontrou forte ressonância na doutrina constitucional brasileira. A adoção dos pressupostos alexyianos não veio sem críticas. Além das críticas feitas à própria teoria, há diversas críticas quanto à forma como ela foi recepcionada, especialmente porque sua utilização acabou favorecendo aquilo que o 
próprio Alexy tentou afastar com a elaboração da fórmula peso e da ponderação: o decisionismo.

Virgílio Afonso da Silva (2003) insurge-se contra o fenômeno que ocorre na doutrina e na jurisprudência brasileira, que ele chama de "sincretismo metodológico", assim definido por ele:

Esse sincretismo metodológico, em termos simples, consiste na adoção de teorias incompatíveis, como se compatíveis fossem. Como exemplo desse fenômeno, pode ser mencionada, para manter-me dentro do tema deste artigo, a recepção da distinção entre regras e princípios e a recepção da chamada teoria estruturante do direito, difundida no Brasil por meio da obra de Friedrich Müller. Um dos traços fundamentais da teoria de Müller é a separação entre programa da norma e âmbito da norma, separação que visa, nas palavras do próprio Müller, a superar a concepção positivista segundo a qual a aplicação do direito seria um mero processo de subsunção do fato a uma norma preexistente a esse mesmo fato. Segundo o autor, isso não passa de uma ilusão, já que a norma não existe antes do confronto com os fatos. Mais do que descer a detalhes da teoria estruturante do direito, o que aqui interessa é salientar uma de suas principais consequências: a rejeição expressa do sopesamento como método de aplicação do direito. Segundo o próprio Müller, o sopesamento é um método irracional, uma mistura de "sugestionamento lingüístico", "pré-compreensões mal esclarecidas" e "envolvimento afetivo em problemas jurídicos concretos", cujo resultado não passa de mera suposição".

(...)

A distinção entre regras e princípios, como foi visto, tem como uma de suas principais características exatamente a exigibilidade de sopesamento de princípios como forma de aplicá-los. (...). Como explicar, porém, que ambas as teorias, a despeito de serem incompatíveis, sejam defendidas, no Brasil, como se complementares fossem?". (SILVA, 2003, p. 625-626).

Essa percepção do autor paulista parece ser a percepção generalizada que a academia tem realizado sobre a ideia de ponderação. Não são somente as críticas à teoria, mas a maneira como ela tem sido realizada, sem qualquer compromisso com a proposta do autor alemão. E isso não significa, definitivamente, que o pensamento jurídico nacional não possa inovar em relação à distinção normoteorética e em relação à argumentação jurídica. Trata-se de uma crítica à ausência de cuidado e rigor intelectual ao trabalhar com o pensamento do autor, e mesclá-lo com contribuições muitas vezes contraditórias, como se a conciliação se desse somente por um ato de boa vontade (SILVA, 2010). 
O objetivo aqui não é aprofundar sobre o sincretismo metodológico e suas críticas, até pela limitação que o trabalho se coloca. A crítica aqui é genérica à forma como a Teoria dos Princípios na doutrina nacional tem sido tratada metodologicamente, por meio de sincretismos de percepções antagônicas, que levam a uma falsa racionalidade decisória, escondendo, de fato o subjetivismo presente na forma de decidir.

O sincretismo metodológico se não for bem estruturado, acaba gerando um arcabouço teórico com pilastras incompatíveis entre si, trazendo mais confusão do que esclarecimento, além de permitir que a argumentação e as decisões judiciais acabem por ganhar contornos ainda mais incontroláveis.

Uma abordagem da doutrina brasileira que parece ser cuidadosa no trato com o marco teórico é a abordagem realizada por Thomas Bustamante. O autor adota as premissas alexyanas como ponto de referência para a elaboração de suas contribuições teóricas, embora deixe claro que sua adesão não é incondicional (2005, p. 139).

As sugestões de aprimoramento da teoria dos princípios se dão de maneira clara, e abordando os pontos de convergência e divergência, evitando transparecer ao leitor que há uma linha de continuidade, como se o pensamento adotado fosse integralmente de Alexy.

$\mathrm{O}$ autor defendendo a teoria alemã ${ }^{2}$, afirma que:

A grande novidade desse modelo [de regras e princípios] é que, junto com ele, surge uma nova metodologia jurídica, haja vista que já não é possível utilizar as mesmas regras e formas argumentativas para justificar a aplicação de regras ou de princípios. A ideia de que a maioria dos direitos fundamentais vêm protegidos por princípios faz nascer, também, a necessidade de uma teoria da argumentação jusfundamental, sem a qual dificilmente se poderá conceber a ponderação como um procedimento racional de justificação jurídica. É essa "argumentação jusfundamental" que pode fazer com que a ponderação seja mais que um arbitrário "modelo de decisão". (BUSTAMANTE, 2006, p. 79).

A concepção de racionalidade jurídica de Alexy demonstra a vocação prática de sua teoria, construindo uma teoria dos direitos fundamentais baseada principalmente em uma teoria da argumentação de cunho procedimental. Por meio dela, objetiva formular juízos

\footnotetext{
2 Thomas Bustamante traz diversas contribuições acerca da teoria de Alexy. Foca-se aqui neste trabalho na questão relativa à argumentação jurídica e a teoria dos princípios.
} 
acerca da correção de enunciados normativos, os quais poderiam ser verificados após o cumprimento de certas regras de argumentação que definem fundamentos do discurso prático.

A preocupação maior da teoria é garantir alguma racionalidade às decisões judiciais, através do estabelecimento de regras de argumentação, que se pode chamar de código da razão prática (BUSTAMANTE, 2006, p. 78). Entre as ideias fundamentais do autor, destacase "a tese de que é possível uma concepção procedimental da razão prática guiada por um conjunto de regras de argumentação, cuja observância garante a racionalidade das decisões encontradas" (ATIENZA, 2001, p. 671).

\section{3 - A FÓRMULA PESO}

A partir dessas constatações, Bustamante revisita a fórmula peso, explicando-a conforme os cânones desenvolvidos por Alexy. Uma das preocupações do autor brasileiro diz respeito à determinação do peso abstrato dos princípios ponderados, os quais exigiriam diretrizes adequadas para sua determinação e a construção de uma classificação dos princípios jurídicos em geral por meio de critérios para o enquadramento de cada um deles nessa classificação. (BUSTAMANTE, 2006, p. 98-99). Mas segundo o autor, é preciso ter cuidado com esse tipo de preocupação, já que

Do ponto de vista jurídico-formal, não existe e nem poderia existir hierarquia entre os vários princípios que estão consagrados na Constituição. Todos foram produzidos da mesma forma e integram o mesmo corpo de normas que constitui a Lei Fundamental do Estado. Todavia, nem por isso devemos ser ingênuos ao ponto de concluir que não exista um certo tipo de hierarquia axiológica entre os enunciados principiológicos.

De fato, a própria Constituição deixa clara a maior importância dos princípios fundamentais em relação aos demais princípios jurídicos. Ao fazer uma valoração acerca da importância dos princípios jurídicos se está a hierarquizar princípios e valores constitucionais, embora não se trate de uma hierarquia rígida entre normas jurídicas. (BUSTAMANTE, 2006, p. 99).

A classificação que Bustamante propõe leva em conta a classificação dos princípios em três grupos, de acordo com a possibilidade de sua restrição: 
$4^{3}$ ) princípios de restringibilidade excepcional;

2) princípios de restringibilidade ocasional; e

1) princípios de restringibilidade ordinária.

Como se pode notar, o critério não foi o da generalidade, como acontece com outras classificações, mas o grau de dificuldade para a superação concreta de cada princípio jurídico. Muito embora tal critério acabe envolvendo uma distinção quantitativa, é bem verdade que ela é cuidadosa com a distinção normoteorética entre princípios e regras, pois tais distinções referem-se somente àquilo que se pode considerar como uma norma princípio. Nesse ponto, o autor adota como alternativa classificatória a que foi proposta pelo português Gomes Canotilho (1991). Eis:

Entre as várias sistematizações possíveis dos princípios jurídicos, chama a atenção a de Gomes Canotilho, de acordo com o qual a Constituição é formada por regras e princípios de diferentes graus de concretização, de modo que existam alguns princípios fundamentais (os denominados princípios estruturantes) que acabam sendo densificados através de uma série de subprincípios e regras mais particulares. A Constituição poderia ser descrita como um sistema interno de regras e princípios, cuja coerência seria garantida pelo esclarecimento recíproco entre os princípios mais específicos e os mais abrangentes. (BUSTAMANTE, 2006, p. 100)

Mas a classificação teórica de Canotilho, embora interessante, não basta para determinar os pesos abstratos, pois os elementos tomados como critério para a tipificação dos princípios, qual seja a concretização e a importância para o sistema jurídico, não constituem única variável relevante. Assim, Bustamante, desenvolve um modelo mais complexo baseado no grau de restringilidade, estabelecendo parâmetros para o enquadramento em cada um dos três níveis supramencionados de superabilidade prática.

Os critérios estabelecidos pelo autor são os seguintes:

a) critério da importância para a coerência do sistema jurídico, sendo preciso constatar que o postulado da coerência está na raiz da própria noção de sistema (BUSTAMANTE, 2006, p. 102-104);

\footnotetext{
${ }^{3}$ Como o leitor pode perceber, adotou-se uma numeração diferente para o caso. Os números referem-se ao peso de cada princípio na fórmula de ponderação. De forma bem simplificada, cada número refere-se ao peso de um princípio. Ou seja, os princípios de restringibilidade excepcional, possuem peso 4 etc....
} 
b) critério da ligação com direitos individuais, sendo que a "precedência prima facie dos direitos individuais sobre os bens coletivos resulta da necessidade de uma ordem normativa e social que leve a sério o individuo como tal". Isso não significa que direitos individuais nunca devem ser afastados em favor de bens coletivos, mas que isso exige razões mais fortes se estivesse na relação contrária (BUSTAMANTE, 2006, p. 104); e

\section{c) precedência prima facie dos princípios da liberdade e da igualdade} (BUSTAMANTE, 2006, p. 104).

Como se vê, adota-se, portanto, a verificação da possibilidade de restrição de um princípio, por base em uma estrutura classificatória que leva em conta o sistema interno constitucional de disposição das normas jurídicas. Não se vai esmiuçar tais classificações, pois o que interessa aqui é o desenvolvimento da teoria da argumentação de Alexy para o terreno das decisões contra legem, terreno sobre o qual Alexy não teria avançado (2005, p. 3).

Pois bem, antes de seguir, destaca-se que é possível constatar nesse caso uma mistura entre os critérios quantitativos e qualitativos da distinção. A proposta, levando em conta a hierarquia dada pela Constituição, distingue princípios e regras de maneira qualitativa, sem confundi-los. Ademais, a hierarquização realizada pelo constituinte só é relevante para um pedaço da fórmula peso, e não para a ponderação como um todo. Ou seja, trata-se somente de estabelecer um critério para se encontrar o peso abstrato dos princípios, e numerá-los de acordo com um dos elementos da fórmula, e não o conjunto deles. Para o professor da Universidade Federal de Minas Gerais:

O conteúdo teleológico, o caráter prima facie, a vagueza, a generalidade e o qualificativo de mandados de otimização impedem que, no campo dos princípios, seja possível qualquer tipo de classificação rígida, ou seja, formulada por meio de conceitos com pretensão de exaustividade. A fim de saber quando cada princípio deverá ser enquadrado em cada uma das três faixas de restringibilidade, só é possível estabelecer critérios móveis (...) (BUSTAMANTE, 2006, p. 101).

Tais considerações são importantes, pois a preocupação de Bustamante é complementar a teoria de Alexy, avançando sobre a discussão sobre a superabilidade de normas jurídicas válidas, ou seja, a possibilidade de restrição de um princípio, ampliando o código da razão prática, aderindo a ele metanormas específicas para a fundamentação de decisões contrárias aos textos legais (BUSTAMANTE, 2005, p. 3; 2010b, p. 153). 


\section{4 - A SUPERABILIDADE DE NORMAS JURÍDICAS VÁLIDAS}

As normas jurídicas seriam sempre superáveis. Isso significa que certas situações exigem que as normas não sejam aplicadas, ou que sejam aplicadas em sentido diferente do extraído do enunciado normativo. Isso se daria porque o sistema jurídico recorre não só às normas em vigor, mas a um sistema de valores que estão implicitamente consignados. Os limites da precisão normativa e da exaustividade dos enunciados dão origem ao reconhecimento de que todo condicional jurídico está sujeito a exceções, que surgem diante dos casos particulares. A aplicação da regra jurídica seria somente ordinariamente necessária e presumidamente suficiente (BUSTAMANTE, 2005, p. 233).

$\mathrm{O}$ reconhecimento da superabilidade das normas jurídicas leva à discussão sobre as diferentes formas de superabilidade e os modos de fundamentação para a superação prática delas. Para o autor, enquanto, no caso específico das regras, a superabilidade "diz respeito a situações excepcionais, as quais tenham sido imprevistas e imprevisíveis quando da criação do enunciado normativo que as originaram”, exigindo argumentação mais forte quanto maior é o componente descritivo-comportamental presente na moldura normativa, os princípios possuem superação imanente, não havendo obstáculos institucionais para sua superação. (BUSTAMANTE, 2005, p. 234-235).

Assim, uma regra seria superada pela criação de uma exceção, demandando uma rigorosa observância de metanormas que compõe o código da razão prática, incrementado pelo autor. Tal conjunto de regras ou princípios de argumentação permitiria uma justificação mais segura para fundamentar decisões contrárias aos textos legislativos. (BUSTAMANTE, 2005, p.240; p.294). Já os princípios seriam superados pela ponderação, que teria como resultado a solução do problema da colisão, criando-se, para expressar o resultado, uma regra capaz de pôr fim a disputar e indicar o comportamento devido. O código da razão prática nesse caso já teria sido desenvolvido por Alexy, merecendo apenas algumas emendas pelo autor (BUSTAMANTE, 2005, p. 239-240).

Não vale a pena aqui detalhar essas normas da argumentação, pois a conclusão acima, posteriormente é revista por Bustamante (2010a; 2010b): 
Basicamente, eu sustentava no trabalho anterior que a superabilidade era uma propriedade tanto dos princípios quanto das regras jurídicas. Os princípios seriam normas cuja superabilidade é imanente, ao passo que as regras seriam normas cuja superabilidade é reservada para casos excepcionais (BUSTAMANTE, 2005, p. 220). Esta tese apresenta semelhanças com o entendimento de Humberto ÁVILA (2010, p. 105), para quem "as regras possuem um caráter 'prima facie' forte e superabilidade mais rígida", ao passo que os princípios tem um caráter 'prima facie' fraco e superabilidade mais flexível". A principal razão pela qual me afasto deste tipo de explicação do fenômeno da superabilidade é que penso que esta explicação não leva em consideração o fato de os princípios serem normas cuja institucionalização é parcial (já que falta a determinação dos comportamentos concretos que se seguem dessas normas) e, por conseguinte, não poderem ser superadas porque elas não estabelecem nenhuma hipótese de incidência. Os princípios estabelecem apenas uma obrigação de otimizar. Se a superabilidade for definida como a possibilidade de se inserir exceções em uma norma jurídica, então deve-se necessariamente presumir que essa norma tenha a estrutura de uma regra que permita a subsunção de certos fatos ou condutas em sua hipótese de incidência. A tese de que a superabilidade é uma propriedade das regras, e não dos princípios, foi também defendida recentemente por Carsten Bäcker (BUSTAMANTE, 2010a, p. 153).

Bustamante abandona a característica de superabilidade dos princípios, pois superabilidade passa a se relacionar exclusivamente com a possibilidade de se inserir exceções em uma norma, e não com a ponderação ${ }^{4}$. Pois bem, para as regras da ponderação, como o próprio autor defende, o modelo de Alexy já seria o bastante. A contribuição do autor, portanto, seria o desenvolvimento de um modelo argumentativo para justificar as decisões contra legem.

Para o autor a introdução de exceções à hipótese de incidência de uma regra jurídica pode se justificar quando um princípio colide com esta regra. Isso significa que Bustamante admite a hipótese de colisão entre regra e princípio, e que os princípios são os requisitos para verificar a superabilidade da norma.

Para compreender, portanto, a proposta do autor, é preciso compreender que reconhecer que a regra é superável não significa abandonar a sua pretensão de universalidade. A introdução de uma exceção baseada em um caso só será justificável se for enunciada em

\footnotetext{
${ }^{4} \mathrm{O}$ argumento de Bustamante leva a consideração de que o autor dá relevo ao critério de distinção entre regra e princípio pelo caráter hipotético-condicional, que estaria presente nas regras e não nos princípios, uma vez que os princípios não seriam superáveis pois não possuem hipótese de incidência, característica exclusiva das regras. Neste mesmo sentido Bustamante, 2005, p. 216-218.
} 
termos universais, sendo possível a sua aplicação a todos os casos semelhantes, exceto, claro, se houver razões fortes em sentido contrário. Em razão disso,

O modelo que se pretende estabelecer para as decisões contra legem caminha, portanto, na direção contrária a qualquer tipo de particularismo jurídico. Se uma exceção a uma determinada regra jurídica não puder ser universalmente estabelecida, essa exceção não poderá ser justificada de forma correta. (BUSTAMANTE, 2010b, p. 157).

Outro pressuposto que deve ser levado em conta é que o discurso jurídico jamais pode abrir mão da pretensão de correção baseado em argumentos morais, pois se a decisão judicial não satisfizer as exigências de uma moralidade procedimental universalista pressupondo um construtivismo ético a la Habermas -, esta será uma decisão defeituosa por razões conceituais. A própria ideia de princípios fundamentais da Constituição é a ideia de uma moral institucionalizada pelo direito.

A regra nada mais é do que o resultado da ponderação de princípios realizada pelo legislador, que define uma solução com pretensão de definitividade. Sendo uma pretensão, não é uma garantia. Uma sociedade dinâmica não poderia gerar regras fechadas e eternas. Para Bustamante, "quando se fala em uma pretensão, obviamente se refere a algo que deve ser vindicado ou resgatado discursivamente" (2010b, p. 160). Isso leva à conclusão de que se a pretensão não é bem-sucedida, dá-se lugar a superabilidade.

Está aí a natureza do caráter prima facie das regras jurídicas, ou seja, a possibilidade delas serem superadas. O que constitui o fundamento dessa possibilidade, para Bustamante, nada mais é do que a irradiação dos princípios sob todo o ordenamento jurídico:

Aplicam-se nesse terreno técnicas como a redução de uma norma jurídica, que consiste na "eliminação de parte do núcleo linguisticamente incontroverso" de uma norma jurídica, ou seja, na introdução de uma "cláusula de exceção" em uma norma estabelecida pelo legislador com fundamento em um princípio. Estabelece-se, porém, uma carga de argumentação especial para quem advogar a não-aplicação de uma regra a uma situação coberta por sua hipótese de incidência, pois sempre haverá princípios formais (ou, como poderíamos chamar, princípios institucionais) que laboram em favor da manutenção das consequências da regra estabelecida pelo legislador. Para se criar uma exceção a uma enumeração taxativa em um dispositivo legal, é necessário incluir no processo de ponderação 
princípios formais como o princípio democrático, o princípio do Estado de Direito e os demais princípios que justificam as regras do processo legislativo, demonstrando que há razões inclusive para superar o peso do material institucionalmente estabelecido pelo legislador. (BUSTAMANTE, 2010b, p. 161).

Isso geraria, conforme diversos autores defendem, e o próprio Bustamante reconhece, a "criação do Direito via interpretação", impondo ao jurista prático uma pesada carga de argumentação. Por mais que as regras se caracterizem pelo componente descritivo permitindo a dedução, pós-interpretação, de um comportamento devido, elas são criadas pelo legislador com base em informações limitadas, cabendo, sempre, adicionar informações que tornem essa regra inaplicável, pois construída sem essa nova informação. (BUSTAMANTE, 2010b, p. 162).

\subsection{ESPÉCIES DE CONFLITOS NORMATIVOS E AS DECISÕES CONTRA LEGEM}

A criação de uma exceção à regra gera uma exclusão da regra original, reconhecendo que aquele caso não se submete à hipótese de incidência, mas não gera sua invalidade, que seria o reconhecimento de sua incapacidade de produzir efeitos jurídicos universalmente.

Para Bustamante, portanto, haveria duas espécies de conflitos normativos em sentido amplo: os conflitos em sentido estrito e as colisões.

O primeiro, os conflitos em sentido estrito se caracterizam pelo choque entre duas normas jurídicas que resulta na declaração de invalidade de uma delas. Isso pode ocorrer tanto com regras quanto com princípios. Para os casos de conflitos de regras, tem-se as já tradicionais observações sobre as antinomias jurídicas, solucionadas pelas regras cronológicas, de hierarquia e as de especialidade. Para o caso dos princípios, o autor exemplifica com o choque entre o princípio da igualdade e princípios que admitissem o sistema de segregação racial, consagrando a superioridade de um grupo de seres humanos. Desse conflito, um deles, o da segregação racial, deverá ser declarado inválido, pois não 
admitido em si, pelo seu conteúdo pela ordem democrática constitucional contemporânea (BUSTAMANTE, 2010b, 166-167).

Os outros conflitos denominados de colisão são resolvidos na dimensão da aplicabilidade, ou seja, ambos continuam válidos, só sua aplicabilidade que é restringida. “O exemplo clássico é a ponderação de princípios” (BUSTAMANTE, 2010b, p. 167).

Não há colisão entre regras, pois, ou uma é declarara inválida, pelos critérios já mencionados, ou ela é excepcionada pela introdução de uma cláusula de exceção. Só que para o autor "essa circunstância não exclui, porém, a possibilidade de uma regra jurídica entrar em colisão com um princípio" (BUSTAMANTE, 2010b, p168). É por causa desse conflito que se pode admitir que uma regra seja superada eventualmente.

Quatro são os conflitos normativos, no mesmo nível hierárquico, que são apresentados por Bustamante (2010b, p. 169):

a) conflito (em sentido estrito) entre um princípio e uma regra: neste caso, a prevalência é da regra, pois a ponderação já foi realizada pelo legislador e a prioridade da decisão é dele;

b) colisão entre um princípio e outro princípio: o método é da ponderação, já apresentado;

c) conflito (em sentido estrito) entre duas regras: esse conflito é resolvido pelas regras de solução das antinomias aparentes, pelo critério da especialidade, hierarquia e cronológico, ou no caso de um conflito genuíno - que não possa ser solucionado pela aplicação desses critérios -, "o intérprete pode se valer dos princípios constitucionais gerais para tentar encontrar uma solução conciliadora e se aproximar de uma interpretação que elimine a antinomia" (BUSTAMANTE, 2010b, p.170); e

d) conflito (em sentido estrito) entre dois princípios: esse caso é raro em nível constitucional, ocorrendo mais no plano da legislação ordinária. Aplicam-se as mesmas diretrizes para solucionar os conflitos entre regras jurídicas.

Mas interessam, também, os conflitos normativos de níveis hierárquicos diferentes. O autor apresenta seis hipóteses de conflitos em sentido amplo, restringindo-se às situações de conflitos entre normas constitucionais e normas infraconstitucionais ${ }^{5}$ :

\footnotetext{
5 Deixa-se de lado, para esta análise, os precedentes judiciais e as normas expedidas pela administração no exercício de seu poder regulamentar.
} 
a) conflito (em sentido estrito) entre uma regra constitucional e uma regra infraconstitucional: refere-se a um conflito que diz respeito à validade, resolvidos pelo critério hierárquico que invalida a norma infraconstitucional;

b) colisão entre uma regra constitucional e um princípio infraconstitucional: refere-se a problemas de aplicabilidade das normas, de modo que o afastamento da aplicação da norma não afeta sua validade geral.

Nesse caso, a regra constitucional excluirá aplicação do princípio aos casos que ela prevê, permanecendo ele a gerar razões contributivas para as hipóteses não cobertas pelas regra;

c) conflito (em sentido estrito) entre um princípio constitucional e um princípio infraconstitucional: aqui, como no caso (a), o conflito diz respeito à validade, aplicando-se o critério hierárquico;

d) colisão entre um princípio constitucional e um princípio infraconstitucional: tal como na hipótese (2), trata-se de um problema referente à aplicabilidade das normas jurídicas, não gerando a invalidade da norma afastada.

Bustamante admite que

Embora sejam raros os casos em que um princípio infraconstitucional isoladamente considerado pode prevalecer sobre um princípio constitucional, o princípio infraconstitucional pode ter uma relevância importante quando associado a um princípio constitucional que contribui para a mesma decisão que ele indica. Ele pode, principalmente em casos de lacuna ou obscuridade na legislação positiva, contribuir decisivamente para a solução de uma colisão entre princípios constitucionais (BUSTAMANTE, 2010b, p 171-172).

Há uma prioridade do princípio constitucional sobre o princípio infraconstitucional, mas essa prioridade não se traduz na invalidade do princípio hierarquicamente inferior. Gerase somente no reconhecimento de peso abstrato substancialmente mais elevado a favor do princípio constitucional;

e) conflito (em sentido estrito) entre um princípio constitucional e uma regra infraconstitucional: aqui, como no caso (a) e (c), o conflito refere-se à validade da norma jurídica. Em princípio, a norma infraconstitucional deve ser declarada inválida, embora essa conclusão não possa ser considerada óbvia, já que a própria regra infraconstitucional é o 
produto de uma ponderação - ainda que somente pressuposta - realizada pelo legislador, diante da colisão entre princípios constitucionais.

Para Bustamante,

Embora o legislador possa violar esse princípio se o restringir de forma irracional ou em desconformidade com as exigências processuais estabelecidas pela máxima da proporcionalidade, o princípio democrático estabelece uma presunção de legitimidade para as restrições estabelecidas pelo legislador. Quem quer que argumente pela inconstitucionalidade de uma restrição a um princípio constitucional deve demonstrar que o legislador, ao ponderar esse princípio com o princípio que justifica a regra restritiva, extrapolou os limites da margem de apreciação que lhe fora deixada pelo constituinte. Essa margem de ação, como já se viu, é determinada pelos princípios envolvidos na ponderação. Deve-se ponderar, portanto, os princípios em rota de colisão (o princípio que foi restringido e o princípio que fundamenta a regra restritiva), e essa ponderação pode levar a três situações: (i) a restrição está conclusivamente determinada pela Constituição no caso concreto, ou seja, é possível inferir diretamente da constituição a conclusão de que o princípio P1 deve ser restringido com fundamento em P2; (ii) a restrição está conclusivamente proibida pela Constituição, ou seja, ao se ponderar P1 e P2 se chega com segurança à conclusão de que o princípio restringido tem peso superior ao princípio que justifica sua restrição; (iii) a restrição não está nem conclusivamente proibida nem conclusivamente permitida pelas normas de direito fundamental diretamente instituídas pela Constituição. Nesse último caso, que compreende a vasta maioria de situações, estamos diante da margem de livre apreciação do legislador, e, por conseguinte, a regra infraconstitucional deve prevalecer sobre o princípio constitucional que com ela colide. (BUSTAMANTE, 2010b, p. 171-172).

A dificuldade, portanto, estaria no fato de que os próprios princípios admitem sua restrição (BUSTAMANTE, 2010b, p. 171): e, por fim,

f) colisão entre um princípio constitucional e uma regra infraconstitucional: tal como as hipóteses (b) e (d), refere-se à aplicabilidade das normas jurídicas, referindo-se aos casos excepcionalmente difíceis.

Aqui, o princípio constitucional $\mathrm{P}$, embora não gere razões para se declarar uma norma $\mathrm{N}$ inválida, gera razões para introduzir nela exceções em sua hipótese de incidência. A ponderação se dá não entre princípio e regra, mas entre o princípio constitucional $\mathrm{P}$, e o princípio constitucional por trás da regra $\mathrm{Pr}$, servindo de fundamento axiológico da norma $\mathrm{N}$ 
válida. Ao lado da manutenção da norma $\mathrm{N}$ e de seu fundamento axiológico, estão os princípios formais da segurança jurídico e da democracia, os quais estabelecem que o juiz deve se vincular ao legislador positivo.

Mas excepcionalmente, admitem-se hipóteses de introdução de exceção à regra $\mathrm{N}$ válida e constitucional. Essa hipótese é a que compreende os "casos genuínos de decisões contra legem" (BUSTAMANTE, 2010b, p. 172). Se a solução gera uma decisão contra legem, então a prioridade é do princípio constitucional sobre a regra infraconstitucional.

A conclusão do autor é que a superabilidade das regras jurídicas torna possíveis decisões contra legem, reconhecidas como parte do universo jurídico, embora exijam forte carga argumentativa. Reconhecendo isto, portanto, a contribuição do autor é no sentido de estabelecer diversas exigências para que uma decisão contra legem seja racionalmente justificada.

Assim, uma decisão contra legem será possível, se da aplicação de uma regra N, reconhecidamente válida e constitucional, a um caso, o resultado seja uma situação inconstitucional. São necessários, portanto, o reconhecimento das seguintes condições para a tomada de uma decisão contra legem:

(i) $\mathrm{N}$ é uma norma do tipo regra, e não um princípio jurídico; (ii) $\mathrm{N}$ está expressa em uma lei ou outra fonte formal do direito com igual nível hierárquico; (iii) os significados mínimos ou literais das expressões utilizadas pelo legislador não permitem extrair do texto que serve de base a $\mathrm{N}$ uma norma alternativa que não seja contrariada por tal decisão; (iv) a decisão não reconhece a invalidade de $\mathrm{N}$, mas apenas afasta a sua aplicação a uma situação em que ela é aplicável; (v) não há dúvida de que os fatos que deram origem à decisão podem ser subsumidos em $\mathrm{N}$; (vi) a autoridade que adota essa decisão estabelece uma norma individual formulada em termos universais; e (vii) a decisão levanta uma pretensão de juridicidade para essa norma individual. (BUSTAMANTE, 2010b, p. 174).

Se uma decisão desse tipo, contra legem, é tomada sem levar em conta a pretensão de juridicidade para a norma excepcional, que deve ser formulada em termos universais, o que ocorre é a usurpação das prerrogativas da autoridade que a prolata, deixando de ser um caso de aplicação do direito.

Essa pretensão de juridicidade é algo que tem de ser fundamentado juridicamente em um discurso ou uma argumentação racional a partir 
de um princípio que fornece um conjunto de razões contributivas para a decisão excepcionadora. Como se trata de uma pretensão, não há nenhuma garantia inicial de que essa decisão poderá ser considerada legítima ao final do processo de argumentação. Para se reconhecer a possibilidade de decisões contra legem - sem o que não tem sentido falar em superabilidade das regras legais - é necessário reconhecer não apenas que Hart estava correto em descrever o direito como uma prática social, mas também que Dworkin está correto ao qualificar essa prática social como uma prática argumentativa. (BUSTAMANTE, 2010b, p. 176).

Considerar que o direito é uma prática argumentativa implica dizer que o direito é construído, e não meramente descoberto segundo um método de dedução lógica. Isso é importante, pois só considerando o direito como algo construído é possível admitir a decisão contra legem, e compreender os pressupostos de Bustamante. Mas isso não significa, para o autor, que o processo de argumentação seja livre, pois embora possa se basear em princípios, e por conta disso de conteúdo moral máxima dose de indeterminação, eles possuem o mais alto grau de normatividade (BUSTAMANTE, 2010b, p. 176).

\section{5 - CRÍTICAS À TEORIA}

A teoria de Bustamante é bem engenhosa, mas incorre no mesmo problema que já se apontou, relativo a adoção da distinção entre regras e princípios como padrões normativos exaustivos, e que são aplicados de maneira diversa, inclusive em relação ao conceito de princípio como mandado a ser otimizado.

Fosse essa distinção aplicada ao Direito Tributário, como ficaria a situação da irretroatividade, por exemplo? O modo de operar seria no tudo ou nada: ou o tributo foi veiculado por meio de lei anterior à sua cobrança, ou não.

Mas retoricamente a doutrina o menciona como princípio. Eis que se pode argumentar que isso não interessa, na medida em que o nomen iuris não determina o conteúdo.

O próprio Bustamante poderia argumentar que a irretroatividade tem um aspecto de regra e outro de princípio, na medida em que a irretroatividade das normas devem ser otimizadas, pois ordena a realização de um fim ou um valor (2008, p. 253). Então não seria possível saber de antemão qual a norma, princípio ou regra, só após a solução do caso, de 
modo que não tem nenhuma serventia a distinção como uma teoria da decisão, podendo ter, porém, como teoria da justificação da decisão.

Ainda sobre esse ponto, destacam-se as críticas de Figueroa (1998, p. 408), que reconhece que tanto Dworkin quanto Alexy se esforçam para restringir a arbitrariedade estatal, núcleo do Estado de Direito. Os esforços são louváveis em sua opinião, mas o meio adotado seria inadequado, ou contraproducente, pois acaba legitimando práticas inaceitáveis, como o próprio decisionismo. Ao juízo dele, "los princípios parecem más bien un instrumento de persuasión en favor del no positivismo jurídico que un autêntico argumento antipositivista de peso" (FIGUEROA, 1998, p. 409).

Para ele tanto os argumentos contra a tese forte, como os argumentos contra a tese da conformidade são úteis para a sobrevivência do Estado de Direito. A tese qualitativa enfrenta o dilema do "cavalo de troia", ou seja, as exceções às regras acabariam corrompendo a divisão qualitativa e a tese da conformidade ignora a existência de outros padrões normativos que não as regras. Para ele, a diferença ontológica das regras só é útil funcionalmente, sendo mais adequada a utilização da tese fraca.

Assim, apresenta duas utilidades na distinção, considerando princípio e regra pelo critério da distinção quantitativa:

a) a distinção é pragmática; e

b) a distinção é disposicional.

Em relação à afirmação de que a distinção é meramente pragmática, o autor argumenta que, tal como a distinção entre casos fáceis e difíceis, teoricamente não se pode apontar características que os transforme em ontologicamente diversos. Qualquer norma pode ser princípio, como qualquer norma poderia ser regra, exceto no nível pragmático, em que os juristas trabalham com a distinção com certa claridade. É possível identificar o que se quer dizer, dentro daquela prática, no discurso, o que se refere a princípios ou regras, dependendo inclusive do estado constitucional que se está a vivenciar (FIGUEROA, 2007, p. 368-369). Nesse sentido parece se aliar à ideia de Ávila, acima descrita.

A distinção, também, é meramente disposicional, o que significa dizer que elas são diferenças meramente potenciais. Nos estados constitucionais, todas as normas podem ser derrotáveis. Enquanto os direitos fundamentais são diretamente derrotáveis, outras normas são indiretamente derrotáveis, por meio do efeito da irradiação. Para o autor 
A questão é que, como resultado do efeito de irradiação, toda norma tem a disposição de ter uma exceção ex post sobre bases constitucionais e éticas porque nos Estados Constitucionais toda norma apresenta, ao final, uma base ética. A derrotabilidade jurídica nos Estados Constitucionais é uma mera consequência da derrotabilidade prática sob a teoria do discurso (FIGUEROA, 2007,p. 369, tradução nossa).

A distinção para ele seria entre normas que estão sob um estado constitucional, e normas que não estão sob o estado constitucional (FIGUEROA, 2007, p. 370).

Bustamante, criticando a posição de García Figueroa, apresenta-o como um autor que acaba caindo no nominalismo, posição filosófica que compreende que, no Direito, "equivale a entender os conceitos e expressões utilizadas na dogmática jurídica como meros 'úteis instrumentos de descrição' de sistemas jurídicos particulares" (BUSTAMANTE, 2008, p. 220). Assim, não seria possível desenvolver um conceito geral do Direito, pois cada sistema jurídico teria seus próprios traços. García Figueroa estaria mais interessado em discutir como os sistemas jurídicos nos Estados Constitucionais funcionam, do que o que se deve entender por direito. Isso o levaria a uma posição meramente descritiva. Isso faz sentido, com a posição que ele adota em relação às regras e princípios, como meros instrumentos linguísticos da prática, sem nenhuma característica ontológica própria.

Mas ainda assim, argumenta-se, não seria possível estabelecer uma característica ontológica própria para regras e princípios de maneira abstrata e, se possa classificar todo o ordenamento jurídico de antemão, suficiente para orientar o modo de tomada de decisão.

No máximo pode-se classificar diferentes padrões normativos, levando em conta suas características mais ou menos fluídas, no âmbito da argumentação, há, de fato uma grande dificuldade na determinação ontológica da distinção.

\section{6 - CONSIDERAÇÕES FINAIS}

De alguma forma todos os teóricos do direito acabam por admitir que o ordenamento jurídico parece ser um sistema provisório de normas de condutas e de sanções pelo descumprimento das normas. Ou seja, o sistema jurídico ou é incompleto ou algumas vezes pode gerar injustiças. Logo, nenhum mandado é absolutamente definitivo, no máximo superficialmente definitivo. 
Isso não implica a defesa de um "vale tudo", e não implica admitir as falhas do sistema como algo jurídico. Não, um sistema em que o descumprimento das normas seja uma constante, é um sistema de juridicidade autoritária, o que seria incompatível com a defesa dos direitos fundamentais e individuais. Que eventualmente o sistema falhe, é verdade, como se o sistema político, econômico etc, tentasse a todo custo invadir o sistema jurídico, obtendo eventualmente êxito. O sistema jurídico estável repele essas tentativas ou quando ela obtém êxito, o sistema logo se recompõe.

A essa perspectiva parece aderir Bustamante, ou seja, embora o sistema seja um sistema sempre provisório, o ordenamento jurídico tem uma estabilidade imanente, ou seja, só eventualmente o seu sistema pode ser superado. A superabilidade das normas não é a falha do sistema, pelo contrário é a sua incidência.

Assim, o ponto que parece mais visível e de destaque na obra do autor, é a relevância da perspectiva da superabilidade das normas jurídicas, encaradas aqui sob o enfoque amplo, e não restrito às regras.

Como sugestão, e aqui cruzando a linha sobre os objetivos da conclusão, e levando em conta o falado no texto, pode-se reformular a classificação dos princípios, elaborada quando o autor ainda defendia que princípios também eram superáveis, e adotá-la como uma classificação argumentativa das normas em geral, sem adotar a distinção entre princípios e regras, em três grupos: a) normas de restringibilidade excepcional; b) normas de restringibilidade ocasional; e c) normas de restringibilidade ordinária.

Assim, continuariam válidos os critérios de classificação apontados pelo autor, como o critério da importância para a coerência do sistema jurídico, critério da ligação com direitos individuais, e precedência prima facie dos princípios da liberdade e da igualdade. A eles, incluiria o critério da reversibilidade. Na colisão de normas, a solução para o caso deveria levar em conta a reversibilidade da restrição às normas deixadas de lado. Assim, a norma que pudesse ser reestabelecido mais rápido seria mais fácil de ser afastada. Por exemplo, entre o princípio a vida e o princípio a liberdade de escolha sobre o próprio corpo, como no caso da mãe grávida que foi submetida a cesárea contra a sua vontade, o princípio da liberdade deve ceder ao da vida, pois é mais fácil reestabelecer o dano psicológico da mãe que foi privada do parto normal, do que a vida, que estava em risco, se esse fosse realizado. Esse critério ajudaria no estabelecimento do grau de restringibilidade. 
Por fim, sem querer, obviamente, tratar de forma integral do pensamento do autor, consideramos que, do ponto de vista da Teoria dos Princípios, essas são as considerações essenciais do pensamento de como essa teoria foi construída por um dos pesquisadores brasileiros, embora, possa se perceber que sua teoria, injustamente, não irradiou, como poderia, pelo sistema jurisprudencial brasileiro. Tem-se visto, e aqui com o risco de fazer uma afirmação genérica sem a devida pesquisa, a adoção da teoria da ponderação ou de argumentos dworkianos sem muita sistematicidade e nitidamente voltados para a tomada de decisões subjetivas, com um uso abusivo da obiter dicta. Como se sabe, essa afirmação é forte demais para os limites do trabalho, mas fica aqui como uma provocação e com a certeza de que o autor concordaria.

Ademais, destaca-se que o autor mais recentemente voltou-se para os estudos de precedentes judiciais e recuperou a discussão essencial sobre a integralidade do direito, sob a perspectiva dworkiana. Porém, sua tese e teoria continuam expostas (até porque a tese se desprende do autor, uma vez publicada) e não se tomou conhecimento de que ele tenha reexaminado os argumentos colocados, embora, possa fazê-lo. Correu-se e corre-se o risco aqui, neste artigo de, em se tratando de um autor vivo e jovem, que ainda terá muito o que contribuir, de ter os argumentos aqui contraditados ou invalidados. Por esse motivo, alerta-se ao leitor, que a revisão feita aqui decorreu da análise minuciosa das referências mencionadas, e a elas se limita.

\section{REFERÊNCIAS}

ALEXY, Robert. A fórmula de peso. In: ALEXY, Robert. Constitucionalismo Discursivo. Porto Alegre: Livraria do Advogado, 2007.

ALEXY, Robert. Princípios formais e outros aspectos da Teoria Discursiva do Direito. TRIVISONNO, Alexandre; SALIBA, Aziz; LOPES, Mônica. (ORGS). Rio de Janeiro: Forense Universitária, 2014a.

ALEXY, Robert. Sobre a estrutura dos princípios jurídicos. In: Revista Internacional de Direito Tributário. v. 3. Belo Horizonte: Ed. Del Rey, jan/jun, 2005.

ALEXY, Robert. Teoria Discursiva do Direito. TRIVISONNO, A. T. G. (Organizador e Tradutor). Rio de Janeiro: Forense Universitária, 2014 b.

ALEXY, Robert. Teoria dos Direitos Fundamentais. São Paulo: Malheiros, 2012.

ATIENZA, Manuel. Entrevista a Robert Alexy. DOXA, 24, p. 671-687, 2001. 
ÁVILA, Humberto. Teoria dos princípios: da definição à aplicação dos princípios jurídicos. $13^{a}$ ed. São Paulo: Malheiros, 2012.

BUSTAMANTE, Thomas da Rosa de (Org.). Teoria do Direito e Decisão Racional: Temas de Teoria da Argumentação Jurídica. Rio de Janeiro: Renovar, 2008.

BUSTAMANTE, Thomas da Rosa de. A Distinção estrutural entre princípios e regras e sua importância para a dogmática jurídica - Reposta às objeções de Humberto Ávila ao modelo de Robert Alexy. Revista Trimestral de Direito Civil, Rio de Janeiro, v. 12, p. 153-168, 2002.

BUSTAMANTE, Thomas da Rosa de. Argumentação Contra Legem: A teoria do discurso e a justificação jurídica nos casos mais difíceis. Rio de Janeiro: Renovar, 2005.

BUSTAMANTE, Thomas da Rosa de. Conflictos normativos y decisiones contra legem: una explicación de la derrotabilidad normativa a partir de la distinción entre reglas y principios.

Revista Doxa. Alicante, n. 33, p. 79-108, 2010a.

BUSTAMANTE, Thomas da Rosa de. Princípio, regras e a fórmula de ponderação de Alexy: um modelo funcional para argumentação jurídica? Revista de Direito Constitucional e Internacional, São Paulo, v.14, n.54, p.76-107, jan./mar.2006.

BUSTAMANTE, Thomas da Rosa de. Princípios, regras e conflitos normativos: uma nota sobre a superabilidade das regras jurídicas e as decisões contra legem. Disponível em $<<$ http://direitoestadosociedade.jur.puc-rio.br/media/Artigo7\%20Thomas.pdf $>>$ Direito, Estado e Sociedade. Revista PUC Rio. Rio de Janeiro, v. 37, p. 152-180, jul/dez. 2010b.

BUSTAMANTE, Thomas da Rosa de. Teoria do Precedente Judicial. São Paulo: Editora Noeses, 2012.

CANOTILHO, José Joaquim Gomes. Direito Constitucional e Teoria da Constituição. Coimbra: Almedina; 1991.

CRUZ, Álvaro Ricardo de Souza. Regras e princípios: por uma distinção normoteorética. In: Hermenêutica Jurídica e(m) Debate: o constitucionalismo brasileiro entre a teoria do discurso e a ontologia existencial. Belo Horizonte: Fórum, 2007.

DWORKIN, Ronald. O império do direito. São Paulo: Martins Fontes, 2007.

FIGUEROA, Alfonso García. ¿Existen diferencias entre reglas y princípios en el Estado Constitucional? Algunas notas sobre la teoría de los princípios de Robert Alexy”. In: Alexy, Robert et alli., Derechos sociales y ponderación, Madri: Fundación Coloquio Jurídico Europeo, 2007.

FIGUEROA, Alfonso García. Principios y positivismo jurídico: el no positivismo principialista en las teorías de Ronald Dworkin y Robert Alexy. Madrid: Centro de Estudios Políticos y Constitucionales; 1998. 
GALluPO, Marcelo Campos. A Teoria Discursiva do Direito e a Renovação do Conceito de Princípios Jurídicos. In: Igualdade e diferença. Estado Democrático de Direito a partir do pensamento de Habermas. Belo Horizonte: Mandamentos, 2002.

SILVA, Virgílio Afonso da. Direitos Fundamentais. 2. ${ }^{a}$ ed. São Paulo: Malheiros, 2010.

SILVA, Virgílio Afonso da. Princípios e regras: mitos e equívocos acerca de uma distinção, Revista Latino-Americana de Estudos Constitucionais, n. ${ }^{\circ}$ 1, Belo Horizonte: Del Rey, 2003. 